\title{
Promoting Inclusive Learning Environment through the Implementation of Outcome-based Education: A Case Study in English Sentence Structure Course
}

\author{
Isti Purwaningtyas ${ }^{1}$, Fatimah $^{2}$ \\ \{tyaz_wijaya@ub.ac.id¹,ffat7613@uni.sydney.edu.au²\} \\ Universitas Brawijaya, Indonesia ${ }^{1}$ \\ University of Sydney, Australia ${ }^{2}$
}

\begin{abstract}
To respond the vast changes on recent education system, the Outcome Based Education (OBE) has been introduced as a reform pattern. Focusing on students' learning outcome, this study attempts to have a constructive alignment of Outcome Based Education (OBE) in the English Sentence Structure course. In the harmony of both concepts of OBE and inclusive environment, students are provided with more meaningful experiences. By employing a classroom action research in this study, the result of the study shows that ESS course is appropriate to build students' graduate profile, add more grammatical skills as well as to benefit for future career. As an effort to promote culturally inclusive environment for the students, the suggested frameworks would be on designing the course objectives, teaching materials, teaching and learning activities and also assessment. By fulfilling real life task, students will be able to learn grammar in communicating the messages and negotiating their meanings.
\end{abstract}

Keywords: OBE, Inclusive Environment, Constructive Alignment, ESS Course

\section{Introduction}

Concerns on the facts that education system in higher education has inadequately prepared graduates who are ready to face challenges in work place and real life have escalated in the last few years. Recently, Outcome-Based Curriculum (OBE) has been introduced and implemented in higher education institutions in Indonesia. As a student-centered approach of curriculum design and teaching, OBE highlights the importance of three crucial elements, namely the learning outcomes, teaching methods and assessment used [1][2]. Disconnection between the three elements may trigger problems in achieving a successful learning [3][4][5][6]. In overcoming disconnection between learning outcomes, teaching methods and assessment utilized, Biggs [7] suggests a three-stage models of constructive alignment as an alternative solution. From the model, Rust [4] suggests that all assessment tasks and their criteria need to be clearly and directly related to learning outcomes. Besides, it is also necessary to audit all modules and learning outcomes to ensure that the assessment will cover all course specifications.

Study Program of English Literature (SPEL), as a part of higher education institution, perceives OBE as a tool to support students' success in learning. This kind of curriculum is also implemented to support a culturally inclusive learning environment. Barker et al. [8] state that a culturally inclusive learning environment refer to a learning environment where all students 
and staff recognize, appreciate and make use of the existing differences to create a conducive learning atmosphere. It means that all learners regardless their cultural background, socioeconomic status, religions, and ethnics have equal rights and chances to be actively involved in any learning experiences offered.

Based on data obtained from tracer study and curriculum reviews, well designed and synchronized courses are needed. The researchers, as lecturers at SPEL, also observe that there are not many courses rooting their syllabus in the notions of OBE and constructive alignment. In addition, many of the syllabus design the activities focusing more on achieving the course objectives rather than addressing students' differences. Based on these conditions, the researchers intended to design syllabi of one skill courses offered in SPEL which is in line with the principles of $\mathrm{OBE}$ and constructive alignment to promote culturally inclusive learning environment. English Sentence Structure (ESS) course is selected since the researchers believe that students' mastery in grammar courses plays an important role in the success of mastering other skills and content courses.

\subsection{Outcome-Based Education (OBE) and Constructive Alignment}

According to Wang [9], Outcome-based is an education reform pattern that comes from the United State the last century. He adds that OBE has evolved through years and resulted on a model developed rapidly in the $21^{\text {st }}$ century. In outcome-based curriculum, the design of curriculum is based on the learning outcomes that students have to perform at the end of a certain course [2]. In line with the statement, Harden, Crosby and Davis [10] illustrate OBE as "product defines process". From the definitions given, it can be seen that the idea of outcome-based curriculum encourages curriculum developers to emphasize on students' exit outcome. The learning process and activities during school must generate long-lasting result even after they graduate. Wang [9] further summarizes OBE in three sentences, namely learning that should last for the rest of life; practical, useable teaching and learning; and integration on learning activities that enhance developing critical thinking skills and learning resilience.

In implementing outcome-based curriculum, there are four basic principles, those are clarity of focus, backward design, learning engagement and expanded opportunities [11]. He explains that a course is designed based on the what the students are expected to achieve at the end of the course. The course enables students to achieve the learning objectives, engage deeply with the learning activities and experience various learning opportunities.

During its implementation, OBE applies constructive alignment. Suryadi et al. [11] refers constructive to students' ability to construct meaning through learning experiences. While the term alignment means there is an alignment between teaching-learning activities, assessment and, learning outcomes. Constructive alignment was first introduced in 1996 by John Biggs [12]. Biggs [13] highlights that constructive alignment focuses on how students build their learning through experiences. In the constructive alignment, Biggs (1996, cited in Le, Hoang \& Anh Do [14]) proposes three stage model, starting from identifying clear learning outcomes, designing appropriate assessment tasks, and designing appropriate learning as depicted in Figure 1. 


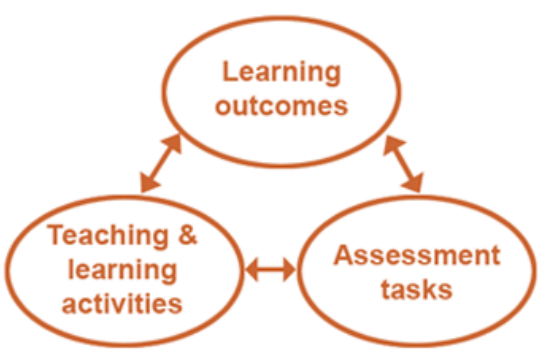

Fig. 1. Constructive alignment (Biggs, 1999 cited in Le, Hoang \& Anh Do [14]).

The concept of constructive alignment is relevant to OBE since its emphasis is on the importance of defining and achieving intended learning outcomes. Figure 1 shows how those three elements are related each other. In designing a curriculum, what students need to learn and how they perform the learning objectives must be carefully selected. Moreover, the teaching and learning activities are specifically chosen to engage students to achieve the intended learning objectives. Finally, assessment tasks are formulated in such ways that allow students to demonstrate their achievement in learning outcomes and enable teachers to distinguish the extent to which the outcomes are accomplished.

By designing a curriculum using the principles of outcome-based education and constructive alignment, it is expected that the course is directed and coherent. Furthermore, the curriculum will eventually generate graduates who are more relevant to the demand of stakeholders. Besides these two notions, a curriculum should also create culturally inclusive environment which will increase students' engagement in their learning process.

\subsection{Culturally Inclusive Environment}

As stated previously in the introduction, culturally inclusive environment is marked by acknowledgement, acceptance and appreciation from all members of an institution that there are differences among them. The differences are then used as tools to develop intercultural communication skills. Barker et al. [8] offers some strategies to create a culturally inclusive environment in classroom as depicted in Figure 2.

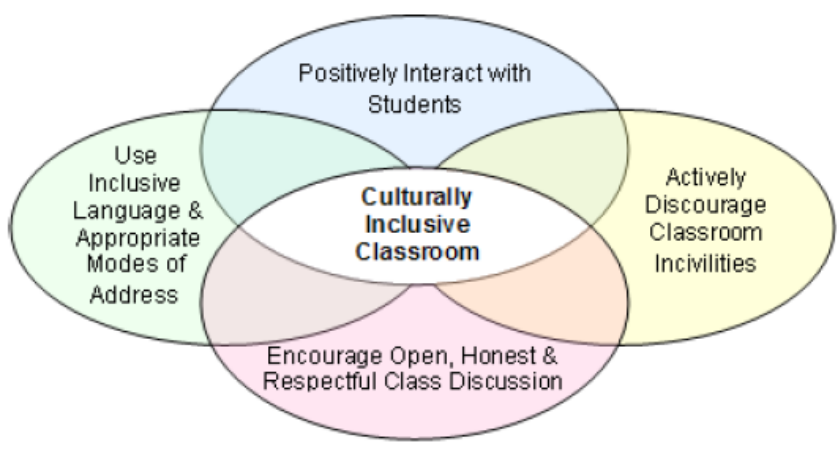

Fig. 2. Recommended strategies to create a culturally inclusive classroom [8]. 
From Figure 2, Barker et al. [8] propose four strategies, namely building a positive interaction with students, using appropriate language and modes of address, encourage open and respectful class discussion, and eliminate classroom incivilities. There are some activities that lecturers can do in their classroom such as holding some activities that elicit students background, celebrate similarities and differences among them, and provide information about teaching-learning activities and instruction [8]. It is also suggested to utilize technologies to build good rapport between lecturers and students.

Based on the researchers' preliminary observation, students who enrolled in Study Program of English (SPEL) come from different places in Indonesia and overseas. According to British Educational Research Association [15], race and ethnicity continue to be major factors which influence children's and adults' experiences of education at all levels and in a variety of aspects. These include academic achievement, professional employment, social interactions, parental involvement, curriculum development, assessment issues. Since students in SPEL have various ethnics, there is a need to address these differences in their learning process. Students need to learn differences in their culture from their peers so that they can respect others and collaborate with others without having prejudices.

\subsection{English Sentence Structure}

English Sentence Structure is a basic grammar course which is offered in the second semester. At the end of the course, the students are expected to acquire some grammatical concepts and apply them in real life. Based on the tracer study and forum group discussions with some experts and stakeholders, graduates from SPEL are required to have qualities such as critical thinking, problem solving, analytical thinking, and team work in their working place. Therefore, the course is designed using materials, techniques and assessment which enable students achieve those qualities.

In this course, the students are encouraged to find differences in the use of selected grammatical concepts in various texts. Students are given opportunities to acknowledge the differences by looking at possible sentence structures and appreciate those differences by analyzing them. In addition, students also have chances to improve their interpersonal skills and team work through group discussion, mini presentation and peer work.

\section{Research Method}

The researchers carried out the study using Classroom Action Research (CAR) design, because they intended to address problems related to teaching learning activities in a classroom. Scrivener [16] defines that action research is a teacher's personal study of his or her own teaching and of the students learning. CAR steps involving reconnaissance, plan, action, observation, implementation and revised plan were carried out in designing OBE syllabus in ESS course to improve students' learning success. The research involved 4 grammar lecturers and 55 students. During the observation, the researchers distributed questionnaires to both lecturers and students to gather information about the challenges in implementing the course outline. 


\section{Result and Discussion}

\subsection{Identifying Learning Outcomes}

Based on the interviews with the grammar lecturers, the researchers found two key issues, namely students' low ability in producing proper sentences in English and materials which are too difficult for students. Having assessed the real condition in ESS course, the researchers in collaboration with the grammar lecturers planned a course outline for ESS subject which covers course description, learning outcomes, course objectives, course materials, assessment system and matrix of the course. The learning outcomes for the course and each meeting are carefully formulated in accordance with higher order thinking skills. Using the notions of outcome-based curriculum, constructive alignment and culturally inclusive environment, the researchers together with the grammar lecturers have formulated four learning objectives for this course. The objectives are (1) understand concepts Questions and Noun Clauses, Indirect Speech, Relative Clauses, and Conditionals which are used in various topics. (2) apply those concepts in both spoken and written communication in different topics. 3) evaluate information in relation to the use of grammatical concepts in both online and offline sources. (4) solve grammatical problems found in texts. These learning outcomes are expected to enhance students learning success and their academic performance. The course outline was introduced to students in action stage, particularly in the beginning of the course. The researchers believe that students have to understand what they are expected to do so that they can prepare themselves better. Due to pandemic, the class were conducted both synchronous and asynchronous modes.

\subsection{Designing Materials}

Having formulated the learning objectives which are aligned with the program learning outcomes, the next step is designing the materials and learning activities. The researchers collaborating with the grammar lecturers selected grammatical patterns that are included in ESS. The grammatical patterns discussed in this course are Questions and Noun Clauses, Indirect Speech, Relative Clauses, and Conditionals. These patterns were selected considering the coverage of previous grammar course and grammar course offered in the next level. Then, the researchers together with the grammar lecturers studied a variety of grammar textbooks available and eventually decided to use "Grammar and Beyond level 3" written by Reppen et al. [17]. This book is published by Cambridge Press. This book was chosen because of two reasons, the first is because it is a communicative grammar textbook which discusses grammar concepts in context. The researchers believe that grammar should be learned in context and not in isolation since students will be able to see how the patterns are used in real life communications. The second reason is because this textbook presents grammar patterns in various topics including cultural values. In detail, the topics presented in this textbook are geographic mobility, cultural values, inventions, human motivation, problem solving, English as a global language, millennial, media in the United States. By having cultural values as one of the topics, the researchers believe that students have opportunities to address and learn different cultural values from their peers. This condition will eventually promote inclusive cultural environment. Moreover, each grammatical pattern is discussed in two or three topics to expose the students to the various use of a particular grammatical pattern in different texts. Each unit starts with a reading text and comprehension questions. Then, students are asked to identify a certain grammatical pattern. Discussions on the selected grammatical pattern is presented 
afterwards. There are some exercises for each of sub unit which can be a form of written or spoken tasks. Furthermore, the tasks are completed individually, in pairs or even in a group. In order words, the tasks are designed using participatory and collaborative principles. By assigning students to have peer and group activities, the lectures encourage their students to interact positively with their peers, practice negotiating ideas using proper language, and have open and respectful discussions. This idea is in line with Barker's [8] strategies to promote inclusive cultural environment.

\subsection{Designing Teaching and Learning Activities}

In designing learning experiences, the researchers and lecturers selected meaningful yet fun activities which enable students to enhance their critical thinking, problem solving skills, and team working. Moreover, each activity is relevant to meet learning outcomes. The researchers and the grammar lecturers considered two principles, namely student-centered learning and task-based learning, in designing the learning experiences. The researchers employed student-centered learning because this approach has been empirically effective to support multicultural environment, since the wide variety of perspectives are welcome. Moreover, task-based learning in which students engage in communicative tasks using most of their time talking, discussing, negotiating, and helping each other learn a language through meaningful communication, is also adopted in ESS class. There are various meaningful yet fun activities in task-based learning that the lecturers can design as it is suggested by Lambert [18]. He mentions that in fostering students' communicative ability, lecturers can implement classroom activities such as expressing feelings through literary genres, arguing and defending a position, interviewing, writing essays, letters, as well as writing and discussing travel plans.

Having considered the students' need, learning objectives in ESS course and lecturers' suggestions and experiences in teaching ESS course, the researchers have decided one learning activities which foster students' critical thinking and collaborative works and it promotes inclusive cultural environment. The activity is essay writing with the theme "Cultural Value". The lecturers divided the students into groups of three. In assigning the groups, the lecturers ensured the ethnic/origin heterogeneity of students within groups. Then, the students were given guideline to do the assignment, i.e., essay writing. The students were required to make an essay outline, write draft, do peer review, revise the draft and proofread the draft. The students were asked to submit their work in each stage so that the lecture could monitor their progress in each step of writing process. Online discussions were conducted to discuss issues that the students had and highlight common errors that students made in their writing. Best students' essays from all ESS classes with various titles were then published in a book entitles "Grammar Stories." Some of the titles of students' essay about cultural values are "Balinese culture", "How Galungan is celebrated", "Tolerance value in Indonesia", "Cultural values in Indonesia", "Multiculturalism in Indonesia", "Family culture", and "Culture as an identity of Indonesia".

As mentioned earlier, the researchers distributed questionnaires to both lecturers and students during the implementation and observation stages. In the reflection of the OBE classes, the students expect to have more varied activities, more discussions, and more readings/supplementary materials. The results of questionnaire distributed to students suggest that in general, the materials and the assessments set in ESS course were suitable with the learning outcomes. Students also found the course beneficial to prepare them for the next courses. Considering the essay writing activity, the students considered this activity as meaningful and effective for them to practice their knowledge in grammar. In addition, they 
also state that they learn about culture more from their readings and discussions with their writing team.

In order to provide a more effective learning environment for both the teachers and the students, a student-centered classroom is found to meet this requirement. The teacher is able to create more activities for the students as well as keeping up with the learning objectives, and the students are also convenient with the changing roles they have in the classroom [19]. Such student-centered learning is also found to be effective to support multicultural environment, since the wide variety of perspectives are welcome.

Another technique to boost the teaching and learning of grammar in the classroom is through the implementation of task-based learning. While doing real life task to practice the communicative skills, the students will be able to exchange messages and negotiate meaning. The teacher does not predetermine the lesson, rather s/he prepares the students to engage in communicative tasks using most of their time talking, discussing, negotiating, and helping each other learn a language through meaningful communication. The real-world pedagogical tasks may include completing various forms, expressing feelings through literary genres, arguing and defending a position, interviewing, writing essays, letters, writing and discussing travel plans, and others which help to foster the learners' communicative ability [18].

\subsection{Designing Assessment Task}

The last stage is designing assessments which align with the learning objectives, materials, and learning activities. The assessments must also be able to measure to what extent the students achieve the intended outcomes. The researchers employ the concept of assessment for learning (AFL) instead of assessment of learning (AOL). AFL which becomes increasingly recognized as crucial in language assessment. uses assessment to promote learning and improve teaching [20]. The researchers believe that AFL give benefits for both students and lecturers. Lecturers can use the result of the assessment to adjust their teaching practices in classroom to enhance learning. Students, on the other hand, can develop critical awareness of how to improve their learning as well as valuate their work and know how to improve on their work. By implementing AFL in classrooms, it is believed to strengthen the link between learning, teaching, and assessment [21].

In ESS course, the students' progress is monitored in every meeting. Students do the exercises in each sub unit either individually, in pairs, or in groups. The exercises vary so that students can apply the grammatical pattern learned in different contexts, such in writing sentences, answering comprehension questions, editing a short text, making dialogue, completing script of an audio dialogues. By having these formative assessments, students can monitor their progress and identify difficulties. Similarly, lecturers can also check students' mastery on each grammatical pattern, identify some possible problems experienced by their students and adjust their teaching-learning activities to address the issues. Besides short exercises, the students are also required to implement the grammatical patterns learned in essay writing. This practice is carried out in groups. By exposing students to various kinds of exercises, students widen their knowledge on grammatical patterns and develop both cognitive and cognitive skills. 


\section{Conclusion}

In providing culturally inclusive environment for the students, the teaching and learning processes need to be designed specifically in student-centered learning. Richards and Schmidt [22] state this learner-centered approach keeps learners to the center of all aspects of language teaching, including planning, teaching and evaluation. By having the active involvement of the students and their interaction with pairs, in groups, and even working individually on the tasks enhance their communicative skills. This research aimed at designing English Sentence Structure course outline using the concept of OBE and a constructive alignment principle. The course successfully creates an inclusive environment which provides more meaningful learning experiences and scaffolds students' grammar competence. It is expected that grammar class will be a lot more meaningful and enjoyable and it can eventually equip students with the mastery of sentence structure as well as other related skills.

\section{References}

[1] R. Killen, "Outcomes-based education: Principles and possibilities," Unpubl. manuscript, Univ. Newcastle, Fac. Educ., 2000.

[2] N. Gunarathne, S. Senaratne, and S. Senanayake, "Outcome-based education in accounting: The case of an accountancy degree program in Sri Lanka," J. Econ. Adm. Sci., 2019.

[3] M. Price, K. Handley, J. Millar, and B. O'donovan, "Feedback: all that effort, but what is the effect?," Assess. Eval. High. Educ., vol. 35, no. 3, pp. 277-289, 2010.

[4] C. Rust, "The impact of assessment on student learning: how can the research literature practically help to inform the development of departmental assessment strategies and learner-centred assessment practices?," Act. Learn. High. Educ., vol. 3, no. 2, pp. 145-158, 2002.

[5] M. Devlin and G. Samarawickrema, "The criteria of effective teaching in a changing higher education context," High. Educ. Res. Dev., vol. 29, no. 2, pp. 111-124, 2010.

[6] G. Petty, Evidence-based teaching. Nelson Thornes, 2009.

[7] J. Biggs, "Assessment and classroom learning: A role for summative assessment?," Assess. Educ. Princ. Policy Pract., vol. 5, no. 1, pp. 103-110, 1998.

[8] M. Barker, E. Frederiks, and B. Farrelly, "GIHE Good Practice Resource Booklet on Designing Culturally Inclusive Learning and Teaching Environments," Extr. Retrieved from, 2009.

[9] J. Wang, "The Comparison and Inspiration of Outcome-based Curriculum Design in Canada and Higher Vocational Education in China," in 2nd International Conference on Management Science and Industrial Engineering (MSIE 2013), 2013.

[10] R. M. Harden, "AMEE Guide No. 14: Outcome-based education: Part 1-An introduction to outcome-based education," Med. Teach., vol. 21, no. 1, pp. 7-14, 1999.

[11] B. Suryadi, F. Ekayanti, and E. Amalia, "An integrated curriculum at an islamic university: perceptions of students and lecturers," Eurasian J. Educ. Res., vol. 18, no. 74, pp. 25-40, 2018.

[12] G. Ruge, O. Tokede, and L. Tivendale, "Implementing constructive alignment in higher education-cross-institutional perspectives from Australia,"High. Educ. Res. Dev., vol. 38, no. 4, pp. 833-848, 2019.

[13] J. Biggs, "Enhancing teaching through constructive alignment," High. Educ., vol. 32, no. 3, pp. 347-364, 1996.

[14] T. Q. Le, D. T. N. Hoang, and T. T. A. Do, "Learning outcomes for training program by CDIO approach applied to mechanical industry 4.0," J. Mech. Eng. Res. Dev., vol. 42, no. 1, pp. 50-55, 2019.

[15] British Research Association (BERA), "Race, ethnicity, and education," British Research Association (BERA), 2021. [Online]. Available: https://www.bera.ac.uk/community/raceethnicity-and-education.

[16] J. Scrivener, "Learning Teaching: A guidebook for English language teacher." Oxford: 
Macmillan, 2005.

[17] L. Blass, S. Iannuzzi, R. Reppen, and A. Savage, Grammar and beyond level 3 student's book, vol. 3. Cambridge University Press, 2012.

[18] C. Lambert, Referent similarity and nominal syntax in task-based language teaching. Springer, 2019.

[19] G. B. Wright, "Student-centered learning in higher education.," Int. J. Teach. Learn. High. Educ., vol. 23, no. 1, pp. 92-97, 2011.

[20] I. Lee and D. Coniam, "Introducing assessment for learning for EFL writing in an assessment of learning examination-driven system in Hong Kong," J. Second Lang. Writ., vol. 22, no. 1, pp. 34 50, 2013.

[21] P. Griffin, Assessment for Teaching. Port Melbourne: Cambridge University Press, 2014.

[22] J. C. Richards and R. W. Schmidt, Longman dictionary of language teaching and applied linguistics. Routledge, 2013. 